\title{
Indícios do sistema coeducativo na formação de professores pelas escolas normais durante o regime republicano em São Paulo (1890/1930)
}

\section{Evidences of the co-educational system in the training of teachers by the normal schools during the republican regime in São Paulo (1890/1930)}

Jane Soares de Almeida*

\section{RESUMO}

O artigo analisa a formação de professores pelas escolas normais em São Paulo no período de 1890 até 1931, época pautada pela adoção no Sistema Escolar do ideário do Iluminismo republicano. De acordo com o espírito de federação que tomou conta do País e as ideias iluministas, alinhadas com o Positivismo e com as concepções liberais, a escola pública devia se aperfeiçoar e expandir. As escolas normais foram as instituições ideais para essa formação e, ao mesmo tempo, indicava-se que as mulheres possuíam todas as qualificações para se encarregarem do ensino de crianças. As tentativas de implantar o sistema coeducativo, visando educação igual para os dois sexos, proposta que sofreu restrições das famílias, dos educadores e da Igreja Católica ocasionaram algumas discussões que acabaram por cair no vazio em vista das questões educacionais mais prementes.

Palavras-chave: escolas normais; formação de professores; coeducação.

* Doutora em História e Filosofia da Educação pela Universidade de São Paulo/SP; Livre Docente pela Universidade Estadual Paulista/SP, Pós-Doutora pela Universidade de Harvard Estados Unidos e pela Universidade Autônoma de Barcelona - Espanha; Pesquisadora do CNPq - Produtividade em Pesquisa; Professora do Programa de Pos-Graduação em Educação pela Universidade Metodista de São Paulo/SP. 


\begin{abstract}
The article analyses the training of teachers by normal schools in Sao Paulo from 1890 to 1931, period guided by the adoption in the school system of ideas of the Republican Enlightenment. According to the spirit of federation that took over the country and the Enlightenment ideas, aligned with the positivism and the liberal conceptions, the public school should be improving and expanding. The normal schools were the ideal institutions for such training and at the same time, indicated that women have all the qualifications to take care of the children education. Attempts to deploy the co-educational system, targeting equal education for the two sexes, proposal which has restrictions on families, educators and the Catholic Church, it caused some discussions that ultimately fall into the void in light of the most pressing educational issues.
\end{abstract}

Keywords: normal schools; training of teachers; co-education.

\title{
Introdução
}

A mudança do regime político no Brasil em finais do Século XIX favoreceu o interesse pelas questões da educação popular, embora a recém-criada República não oferecesse condições efetivas para sua implantação. A necessidade de escola para toda a população obrigou o poder público a investir na formação de professores para atuar na educação de crianças, criando-se para isso as escolas normais, nos moldes das que funcionavam na França. Essas escolas eram instituições precárias que abriam ou fechavam conforme decisões políticas nem sempre de acordo com os parâmetros educacionais exigidos e possuíam limitações orçamentárias significativas que impediam seu bom funcionamento. Nelas era ministrado um tipo de ensino elementar, mais propriamente voltado para aquilo que se deveria ensinar no curso primário do que um aprofundamento de estudos e uma real formação profissional dos alunos que as buscavam. Nas várias províncias brasileiras, a partir de meados do século XIX foram inauguradas algumas escolas normais para atender às necessidades de formação de professores para o ensino primário que tentava expandir-se desde o Império.

Mesmo com intencionalidade explícita de se educar toda a população, o preconceito herdado culturalmente de Portugal forneceu as coordenadas para que a instrução feminina fosse vista com desconfiança e mesmo nas províncias mais desenvolvidas as mulheres viviam em situação de inferioridade e dependência. Nas famílias mais ricas recebiam algumas noções de leitura e escrita, dedicando- 
se ao aprendizado das prendas domésticas, condição mais do que necessária para conseguirem um bom casamento. Há que se atentar que no Império a educação das moças de melhor poder aquisitivo se processava no interior das residências citadinas ou nas casas grandes das fazendas, sob a responsabilidade de pais ou professores contratados, sendo-lhes oferecido um conhecimento que se limitava às prendas domésticas, aprendizagem das primeiras letras, com noções de leitura e escrita, além de música, dança e culinária, em alguns casos a língua francesa (WEREBE, 1963, p. 231).

A partir da metade do século XIX a educação das meninas das famílias de recursos passou a ser confiada aos colégios particulares leigos ou religiosos, mas mesmo a essas jovens privilegiadas eram reduzidas as opções escolares. Portanto, o que não dizer do grosso da população flagrantemente ausente da instrução, tanto homens como mulheres? Nesse contexto, as escolas normais foram vistas como uma alternativa possível para a instrução feminina, além de suprirem a necessidade de mão de obra para um ensino que tinha como meta expandir-se e estender-se à população, de acordo com os ideais liberais e democráticos que passavam a se disseminar com a proximidade da República entre as mentes ilustradas do País. Porém, as primeiras escolas normais eram parcas de recursos, fracas quanto aos programas, ausentes de uma proposta pedagógica coerente quanto aos objetivos de formação de professores, além de não possuírem profissionais habilitados para lecionar. Era uma instituição frágil que não conseguiu nas décadas seguintes se alicerçar no também precário Sistema Escolar, o que somente aconteceu quando as moças passaram a procurar por esse tipo de ensino, que se configurou praticamente como uma das únicas vias de acesso da parcela feminina à educação escolarizada.

\section{As primeiras tentativas de formar professores}

Na primeira Escola Normal da Província de São Paulo constavam as disciplinas que os professores deveriam ensinar no curso primário, com apenas uma matéria de cunho pedagógico denominada Métodos e Processos de Ensino. Essa escola chamou-se Escola Normal Primária. Com duração de dois anos era dirigida apenas aos candidatos do sexo masculino. A influência da Igreja Católica, apesar da sua indisposição com o governo imperial, se manifestava nos programas escolares, numa época marcada pelo espiritualismo eclético e por um pensamento apegado ainda aos valores e tradições europeias. Os currículos apresentavam um perfil humanista e forneciam uma formação geral desvinculada 
de caráter profissional e voltada para especificidades de um mundo social que ainda não definia concretamente seus objetivos, evidenciando a fragilidade de uma experiência escolar que apenas aprofundava os conhecimentos do curso elementar. Mesmo com as novas ideias do cenário ilustrado brasileiro do século $\mathrm{XIX}$, os programas ensinados nas escolas normais continuavam ancorados no tradicionalismo católico europeu, pouco atentando para as mudanças que se anunciavam no período pré-republicano.

Após algumas tentativas infrutíferas de fortalecer a formação de professores, em 1880 se inaugurou a terceira Escola Normal em São Paulo, com curso de três anos, classes mistas e cinco professores ministrando aulas em cinco cadeiras. Essa escola, criada pela Lei n. 130 de 25 de abril de 1880, deu origem ao Instituto de Educação Caetano de Campos da Praça da República. Junto à escola foi criado um curso preparatório anexo, com duas classes, uma para cada sexo. Não houve inovações significativas em seu currículo ou no seu funcionamento, a não ser a introdução das aulas mistas, fato claramente progressista para os padrões da época e com inspiração norte-americana, em que se iniciava uma busca de implantação do sistema coeducativo. Para atender à precisão histórica seria necessário rever objetivamente quando isso foi consolidado, porém não foi possível obter essa informação em vista das dificuldades de se conseguir documentos sobre a coeducação no Brasil.

As mudanças que as ideias pré-republicanas introduziram na sociedade brasileira e a elevação do nível econômico da classe média, juntamente com a influência cultural dos imigrantes europeus, levaram a uma revisão de valores que até então permeavam a sociedade com resquícios do colonialismo. O Positivismo de Comte influenciava fortemente o pensamento político e as mentes ilustradas, impondo-se assim a ideologia da Ordem e do Progresso, conceitos que levariam a Nação ao almejado desenvolvimento. A escravidão, até então considerada mesmo pelos ideólogos liberais como um mal necessário, dada sua importância para a poderosa classe senhorial da antiga colônia, entrou em franco processo de extinção até culminar com a abolição em 1888. Além disso, a separação da Igreja do Estado de forma oficial era iminente e escolas estrangeiras foram inauguradas no país, trazendo inovações nos métodos de ensino e no ideário pedagógico. Nas fronteiras conhecidas da época se discutia a educação como fator de desenvolvimento e o Brasil acompanhava essa tendência. Isso acabou por promover mudanças na imagética social, entre elas, o novo valor atribuído à escola e a necessidade da sua extensão à população, já que o país necessitava de um povo mais esclarecido para poder desenvolver-se e equiparar-se às grandes nações do mundo. No entanto, no plano concreto, a população continuava na mais extrema pobreza e ignorância, com baixos níveis de saúde, alimentação, habitação e naturalmente educação, sendo altos os níveis 
do analfabetismo.

Esse panorama foi propício para que as escolas normais se voltassem para a educação feminina como parte do projeto civilizador da nação e, nesse projeto, também cumprisse as funções de educar e instruir as futuras esposas e mães que seriam encarregadas da educação e do fortalecimento da família. A criação das classes mistas nas escolas primárias e normais passou a ser objeto de debates que nem sempre se alinhavam, mesmo que fosse como experiência pedagógica. Porém, colocar as mulheres para ensinar meninos e meninas foi considerado uma excelente alternativa, uma prática que servia tanto para atender à necessidade de educação feminina, como para preencher os postos no magistério e servir aos objetivos estatais de ampliar a escolaridade da população. O Seminário das Educandas, instituição destinada a educar as órfãs sem dote, abriu um curso de formação de professoras que foi fechado várias vezes por falta de verbas. Alguns anos depois se instituíram classes mistas, com bancos separados para alunos e alunas por uma divisão. Mas no curso preparatório anexo havia duas seções, masculina e feminina e na classe das meninas somente poderiam lecionar professoras (RODRIGUES, 1962, p. 158).

A influência do Positivismo quanto à necessidade de educar as mulheres foi bastante relevante. Os seguidores de Comte admitiam a inferioridade orgânica e intelectual das mulheres, mas as consideravam superiores do ponto de vista moral, o que as fazia merecedoras da abnegada e louvável missão de educar as crianças. Essas ideias, num primeiro momento, rompiam com as ideias anteriores de destinar à parcela feminina apenas a função de procriar, embora mantivessem a estreita relação professora-mãe.

Mesmo com as aspirações desenvolvimentistas e educacionais, no período de transição do Império para a República, as escolas normais, da mesma forma que o sistema educacional, pouca significação tiveram no panorama social do País, cuja classe dominante continuava alinhavando conteúdos literários de inspiração europeia que lhes serviam de apoio na manutenção das relações hegemônicas da sociedade. Após a República, urgia dar continuidade ao projeto civilizador da Nação com a meta de estender a educação para todos, nos moldes de uma ação democrática que visava fortalecer o país, o que poderia ser alcançado pela escola. A formação de bons professores era parte integrante desse projeto e o médico Caetano de Campos foi o encarregado da Reforma do Ensino Primário e Normal no Estado de São Paulo, devidamente orientado pelo seu mentor intelectual, o jornalista Rangel Pestana (REIS FILHO, 1981). Com a incumbência dada a Caetano de Campos, como primeiro passo para a reforma geral da Instrução Pública em 1890, a escola viveu um período áureo e desenvolveu-se, estendendo-se nas décadas seguintes ao interior do estado. Adepto da ideologia veiculada pela Doutrina Positivista, Caetano de Campos 
implantou uma reforma baseada nos princípios da escola pública democrática, universal, gratuita, laica e obrigatória, na qual a formação dos professores seria determinante e fundamental.

Apesar das dificuldades as escolas normais cresceram nos primeiros anos republicanos, assim como o ensino primário, por conta de melhores condições socioeconômicas que também possibilitavam maior desenvolvimento educacional. As tentativas republicanas nem sempre deram certo na organização de um sistema escolar que realmente atendesse às necessidades e expectativas da população, porém o ideal plantado pelo liberalismo de ver a escola como via de ascensão social se solidificou. Num panorama em que as transformações de classe iniciadas no Império se completavam e as camadas médias forneciam o contingente que se dedicaria ao magistério, entre outras profissões, esse contingente marcou também sua presença nos movimentos político-sociais que intentavam estabelecer mudanças na sociedade, entre elas, a crença no poder transformador da educação. Ao longo da República Velha as escolas normais passaram por várias reformas, mas nenhuma tão significativa e que modificasse estruturalmente os modelos anteriores. Houve apenas uma ampliação da cultura geral que lhes dava feições de escola secundária, mantendo a formação propedêutica ainda insuficiente.

As mulheres passaram a se fazer cada vez mais presentes na instituição normalista e a procuravam para obter conhecimentos, preparo para a vida no lar e também ter uma profissão que lhes permitisse sobreviver com seu próprio rendimento. A adequação da profissão de professora às expectativas sociais quanto ao sexo feminino rapidamente levou à feminização do magistério. $\mathrm{O}$ ensino de crianças de tenra idade desempenhado por mulheres implantou na sociedade uma imagética que se alinhava com o valorizado papel materno e a profissão tornou-se bastante popular entre as jovens. Os homens, embora em menor número, também procuravam pelas escolas normais e uma vez ingressos na carreira do magistério buscavam por cargos de chefia e direção, diferentemente das mulheres que permaneciam nas salas de aula.

\section{A coeducação dos sexos nas escolas normais}

Com a crescente entrada das moças nas escolas normais, não mais se discutiria apenas a educação de crianças, mas de jovens em idade de contrair matrimônio, o que duplicava o perigo moral e higiênico. Mesmo entre aqueles que militavam em favor da escola pública não foi visto sem receios um sistema 
único de ensino para moças e rapazes dado que nas escolas normais, educar conjuntamente os dois sexos poderia levar à deterioração da moral e ser um atentado aos costumes tradicionais do País, os quais, segundo alguns, deveriam ser preservados. Portanto, a oposição às classes mistas não teve origem apenas na orientação religiosa, foi também uma questão de costumes e disciplina escolar.

Esperava-se que as futuras professoras aprendessem aquilo que iriam desempenhar no lar, as prendas domésticas, o que impunha um paradoxo: se, de acordo com a ideologia de destinar as mulheres ao ensino de crianças, essas professoras fossem lecionar em classes mistas haveria um problema de difícil solução sobre o que ensinar para os meninos. Isso implicava numa profunda revisão quanto aos papéis sociais reservados aos dois sexos e um embate dificultoso com a ordem natural com que se organizavam a sociedade e os costumes. A perspectiva de que implantar coeducação nas escolas normais permitiria que as jovens aprendessem os mesmos conteúdos destinados aos rapazes, já que também iriam ensinar em classes masculinas, era discutida com veemência pelos defensores do sistema coeducativo. Estes não concordavam, em nome da necessidade de formar quadros profissionais para a educação escolar, com a nocividade dessa prática, condenada pelos defensores dos costumes paulistas tradicionais. Os que defendiam o magistério exercido por mulheres se amparavam numa representação social que se edificava em torno de sua maior facilidade em cuidar de crianças, suas maneiras envolvidas de doçura e paciência, sua afabilidade e bondade, qualidades essas que as distinguiam positivamente dos homens, dado que se ancoravam nos instintos maternais.

Apesar de nas primeiras décadas do século XX as mulheres terem conseguido um maior acesso à instrução e, posteriormente, o direito ao voto e o ingresso no ensino superior, os ideais católicos e positivistas continuaram a impregnar a mentalidade brasileira durante muito tempo. Mesmo com as inovações trazidas pelos missionários protestantes, essa mentalidade tinha a força das tradições longamente herdadas e não mudaria tão facilmente. Quando, pelas mudanças sociais, as classes mistas se tornaram uma realidade nas escolas públicas brasileiras, a maioria dos colégios católicos da época continuou com a tradição de educar os sexos em separado.

A coeducação dos sexos, com seus princípios de propiciar a igualdade entre homens e mulheres num meio sociocultural androcêntrico instaurou um conflito ideológico com a destinação social feminina, erigida desde priscas eras no culto à domesticidade. A independência econômica das mulheres, obtida com o desempenho de uma profissão e sua autonomia intelectual representada por uma educação igual à dos homens, significava a ruptura com acordos estabelecidos e poderia ocasionar desordem social. Mantida dentro de certos 
limites, a instrução feminina não ameaçaria os lares, a família e o homem. Demasiados conhecimentos eram desnecessários, pois poderiam prejudicar a sua frágil constituição física e emocional, além de serem menores suas capacidades intelectuais. Nisso concordavam os católicos brasileiros, os não católicos e até mesmo as próprias mulheres, em vista da força dessa imagética no mundo social. A população, por sua vez, seguia as regras ditadas pelas elites, aprofundando o fosso que separava homens e mulheres.

A ideologia de manter a parcela feminina ausente da instrução, prática acatada na Colônia e no Império, foi parcialmente questionada nos tempos republicanos por força dos discursos positivista e eugênico, que veiculavam a necessidade da educação feminina como forma de se manter a família e a pátria dentro de cânones desejáveis para o desenvolvimento. A corrente higiênica havia plantado a semente da mulher ser a principal responsável pela saúde de seu corpo e dos filhos. Os homens deveriam ser os provedores da família e os guardiões das mulheres. Portanto, a educação deveria encaminhar-se para os objetivos definidos quanto aos papéis sexuais: às mulheres, a reprodução; aos homens, a proteção. Esses valores se estenderiam a todas as áreas: no lar, na política, na economia, na sociabilidade, na religiosidade, nos hábitos e costumes, enfim na própria cultura do período, instalando um imaginário social resistente a mudanças.

\section{Mentes e corpos regrados para a manutenção da ordem social}

Dos finais do século XIX até a metade do século XX, a vida em sociedade, as expectativas sobre os papéis sexuais, as doutrinações da Igreja Católica, as implicações na sexualidade, o controle dos corpos e da mente, a moralidade, mostravam um país preocupado em construir uma sociedade que deveria se expandir sem perder valores tradicionais. As mulheres eram as principais destinatárias de uma ideologia que se centrava na vigilância e na profecia de destinos para cada sexo: ao homem, o espaço público, a política, a gerência de recursos, a liberdade; para a mulher, o espaço privado, a dependência financeira e emocional, a castidade. Nesse contexto, mesmo a educação na mais tenra idade deveria ser enquadrada em normas rígidas para não pôr em risco o desempenho dos papéis reservados a cada sexo. Conscientes dos receios da sociedade de que a mulher educada abandonasse a sagrada missão a ela confiada, a de dar filhos fortes para a Nação, e que isso interferisse na sua saúde e na da prole, mesmo as pioneiras feministas compartilhavam com os homens o ideal de manter a mulher 
no espaço que lhe foi reservado, o mundo da casa. Portanto, o discurso social caracterizou-se dentro dos princípios da ideologia masculina, numa sociedade que se assumia voltada para os valores masculinos e orientada no plano da religiosidade pelo catolicismo.

Os movimentos feministas na Europa e Estados Unidos que se anunciavam ao alvorecer do século XX abalaram parcialmente a visão medieval segundo a qual se acreditava que a educação das mulheres contaminava sua consciência e comprometia a sanidade de seu corpo e de sua alma. As feministas do período defendiam que a saída para romper com os mecanismos que aprisionavam as mulheres no determinismo dos papéis sexuais seria uma educação qualitativamente igual à dos homens. Nesta, se compartilharia os mesmos espaços, os mesmos professores e conteúdos, apesar de não negarem uma educação na qual as noções essenciais para a domesticidade e a pureza moral feminina deveriam continuar sendo transmitidas.

No Brasil, o regime republicano instituiu um código civil em 1916, no qual o homem chefiava a família, administrava os bens, e autorizava o estudo e o trabalho feminino. O amparo legal era o que menos pesava nos comportamentos ditados pela herança portuguesa e derivados das tradições imutáveis desde os tempos da Colônia e que colocavam o homem no centro do universo social e doméstico. No século XX o processo de urbanização promoveu alterações na posição social feminina. Porém, o domínio masculino continuou determinante na organização vigente. Isso porque, apesar de ser considerada superior do ponto de vista moral, era natural que as mulheres ocupassem um lugar inferior na escala social por conta das diferenças entre os sexos e que os homens detivessem as rédeas do poder, num processo no qual a crítica feminista atual denomina a naturalização das diferenças promovendo a desigualdade sexual. $\mathrm{Na}$ organização das escolas, essa ideologia, ao não atingir uniformemente toda a população, dado que se aceitava a não separação dos sexos por medidas de economia, demonstra que por trás disso existia um problema de classe social, ou seja, o que é bom para o povo não o é para as elites.

As ideias coeducativas no cenário da educação pública paulista acompanharam, com alguns anos de atraso, o debate norte-americano do século XIX acerca de meninos e meninas receberem a mesma educação. A insistência da Igreja em se opor ao sistema e o conservadorismo das elites impuseram a separação dos sexos nas escolas privadas de orientação católica e nas públicas, sempre que isso foi possível. O ideal feminista norte-americano, trazido pelas missionárias, defendia que, ao se proporcionar idêntica educação para os dois sexos, se atingiria a igualdade social e familiar, caiu no vazio e as escolas públicas, apesar de estabelecerem meninas e meninos estudando juntos numa mesma sala de aula, separavam alguns conteúdos e atividades por conta de raciocínios 
sexistas, mantendo assim a ordem vigente na sociedade. Também há que se considerar que os protestantes também não deviam estar assim tão convencidos da prudência de se implantar a coeducação num país com ideias tão arraigadas quanto à separação dos sexos. Muitas vezes, durante os primeiros anos da criação dos colégios e das pequenas escolas protestantes junto às igrejas, as classes mistas significavam um momento transitório enquanto não recebiam verbas para construção de classes separadas ou se aguardavam novas professoras.

Nas escolas normais públicas paulistas, é possível defender a hipótese de que a introdução das classes mistas não foi um ato pensado para promover a igualdade, mas uma atitude movida pela necessidade de economia de recursos humanos e materiais. Juntar os dois sexos nas mesmas classes, aprendendo os mesmos conteúdos desafiava os valores morais solidamente arraigados. Além disso, mesmo que recebessem a mesma educação nas escolas, na sociedade as mulheres continuavam destinadas ao lar e à maternidade enquanto os homens se ocupavam das lides do espaço público. A cultura vigente plantara sólidas e firmes raízes na sociedade brasileira na definição dos papéis sexuais e em limitar a responsabilidade feminina às fronteiras domésticas. As ideias progressistas e libertárias dos protestantes norte-americanos, comungadas pelos republicanos, não conseguiram romper com esse padrão. Assim, a complexidade dos debates coeducativos fez com que essa discussão não ultrapassasse o espaço da instituição escolar - as propostas coeducativas eram republicanas e por consequência, de cunho liberal - e a intolerância religiosa com as teses do liberalismo colocaram coeducação e religião católica como antípodas e até a metade do século XX a militância católica impôs sua vontade no cenário social e educacional.

Se nos anos iniciais do século XX houve na cultura brasileira alguns sinais favoráveis à disseminação dos ideais protestantes, divulgados como uma alternativa ao catolicismo, em relação ao sexo feminino não se promoveram avanços significativos. Não se pode esquecer também que a modéstia de recursos das Igrejas Presbiterianas dos Estados Unidos fazia com que os missionários compartilhassem os mesmos problemas de verbas das escolas brasileiras. No país de origem dos missionários, a ideologia de delimitar espaços para cada sexo também foi uma realidade. Com a ofensiva católica na primeira metade do século $\mathrm{XX}$ muitas escolas protestantes fecharam suas portas e a proposta de se estender uma educação igual para os dois sexos ficou limitada a colocá-los em classes onde assistiam às aulas com os mesmos professores, os mesmos métodos e sob a mesma direção. Quanto à projeção da futura vida social para cada sexo, não havia discordância entre católicos e protestantes. Fora da escola tudo permaneceu como antes: o homem mandava, a mulher obedecia. $\mathrm{O}$ homem cuidava, a mulher pertencia. Mediando essa relação, a educação escolar prosseguia como uma forma de controle social e controle de gênero, mesmo embutindo em seu 
discurso a perspectiva da igualdade, da liberdade e da cidadania. Num país que durante décadas acreditou na superioridade masculina sobre a feminina, não seria assim tão fácil romper com essa pretensa supremacia.

\section{As décadas de 1920/30: escolas normais em toda a Nação brasileira}

Com o desenvolvimento do processo de industrialização e urbanização, as condições de vida e de trabalho se modificaram e nos principais centros urbanos a classe média passou a ter ainda maior evidência, ao mesmo tempo em que surgiram líderes políticos dela oriundos, enquanto se formava um núcleo ainda pequeno do segmento proletário, que aos poucos se estruturava. Essas mudanças se refletiram na ordem de poder com a burguesia industrial e financeira apoiada pelas classes médias urbanas, que disputavam o controle do estado com as oligarquias rurais, que eram os tradicionais grupos dominantes. Posteriormente foram deslocadas do poder pela crise econômica que se desencadeou no setor cafeeiro. Isso promoveu mudanças na organização social e as filhas dos oligarcas falidos pela quebra financeira, pressionadas pela urgência econômica, se sentaram nos bancos escolares da Escola Normal, juntamente com as jovens filhas de comerciantes, profissionais liberais e pequenos fazendeiros.

Os anos 1920/30 foram pródigos em reformas e inovações na Escola Normal do Estado de São Paulo e promoveram a ampliação do curso aos interessados em se dedicar ao magistério com a disseminação de escolas normais livres e particulares, principalmente pelo interior do estado. As escolas primárias continuavam precárias e sem condições materiais como espaço físico, mobiliário e material didático, o que contrariava o ideal da escola para todos, apregoado nas intenções dos republicanos liberais. A expansão da demanda pela escola não refletia as necessidades efetivas do desenvolvimento econômico por sua insuficiência e por caminhar em sentido inverso ao das necessidades criadas. Isso promoveu um aprofundamento do abismo existente entre a educação e o desenvolvimento. Mais uma vez, alinhada ao poder dominante, a educação desempenhou o mesmo papel conservador dos anos pré-republicanos.

A parcela feminina da população reclamava maior nível de instrução e a Escola Normal se tornou bastante procurada pelas jovens paulistas oriundas não apenas da classe média, mas também das famílias mais abastadas do estado por oferecer a oportunidade de prosseguimento de estudos. Para a admissão na escola era exigida a verificação da idade, da saúde, da inteligência e personalidade, fato que demonstra a elitização do curso no período, nos rastros de uma política 
educacional bastante autoritária. Para as moças era ainda necessário apresentar autorização do pai ou do marido no ato da matrícula ${ }^{1}$.

A Conferência Nacional de Educação realizada em 1931 e a publicação do Manifesto dos Pioneiros da Escola Nova em 1932 demonstraram inequivocamente a crença de ser a escola um poderoso instrumento de transformação social, atuando também como um aparelho de equalização de oportunidades para o indivíduo e corrigindo a injustiça social, além de possuir o poder de suprir as deficiências de um meio social desfavorável ao educando. A declarada função social atribuída à escola pelo Manifesto, levou a novas preocupações com a formação de professores, considerados os responsáveis diretos pelo sucesso educacional. Porém, a expansão da demanda pela escola não refletiria as necessidades efetivas do desenvolvimento econômico por sua insuficiência e por caminhar em sentido inverso ao das necessidades criadas. Isso promoveu um aprofundamento do abismo existente entre a educação e o desenvolvimento, mais uma vez alinhada ao poder dominante, acabaria por desempenhar o mesmo papel conservador dos anos pré-republicanos.

1 Não é demais apontar que essa atitude possuía paralelos em outros países, o que reitera a universalidade da subjugação feminina também no magistério. Por isso julguei oportuno transcrever abaixo modelo de contrato de trabalho de 1923 que era assinado pelas professoras na sua nomeação na cidade de San Salvador, América Central. Consegui esse documento de colegas quando estive num encontro de historiadores em Havana, Cuba, em 2003, o qual transcrevo a seguir, já traduzido do espanhol. Porém, não consegui localizar a fonte de procedência do referido documento, que é fotocopiado:

Exemplo de modelo de contrato de trabalho de professoras no ano de 1923.

A professora, senhorita......................, por meio deste contrato de trabalho fica obrigada a:

1. Ministrar aulas na Escola....................durante o tempo de vigência do contrato de trabalho.

2. Comportar-se com decoro e vestir-se com modéstia e asseio.

3. Não sair de casa no período entre 18 horas da tarde e 6 horas da manhã.

4. Não passear em sorveterias do centro da cidade.

5. Não sair de carro ou automóvel em companhia de homens, a não ser seus pais e irmãos.

6. Não usar saias e vestidos a menos de um palmo do tornozelo.

7. Não fumar, não beber uísque, vinho e cerveja.

8. Não usar maquilagem e tingir o cabelo.

9. Não usar palavras impróprias que ofendam sua pessoa e sua profissão.

10. Limpar a sala de aula antes dos alunos chegarem.

11. Cuidar da limpeza, da higiene e da moralidade da sua sala de aula.

$\underline{\text { O não cumprimento das obrigações acima implicará na sua demissão imediata e justa. }}$ 


\section{Considerações finais}

Apesar das conquistas efetivadas ao longo das primeiras décadas do século $\mathrm{XX}$ como o acesso das mulheres ao ensino superior e a algumas profissões, esses ideais permaneceriam, por longo tempo, impregnando a mentalidade brasileira e esculpindo uma figura de mulher plasmada nesse perfil. A responsabilidade feminina nunca deveria transpor as fronteiras do lar, nem ser objeto de trabalho assalariado. O trabalho somente poderia ser lícito se significasse cuidar de alguém, doar-se com nobreza e resignação, e servir com submissão, qualidades inerentes às mulheres, premissas com as quais também se afinavam profissões ligadas à saúde, como enfermeira ou parteira.

Na primeira metade do século $\mathrm{XX}$ as escolas normais se firmaram como instituições procuradas pelos segmentos médios da população. As cidades do interior viram florescer vários estabelecimentos de ensino para onde iam as filhas dos fazendeiros, dos ricos negociantes e profissionais liberais da região onde se localizavam. Dentre os colégios católicos destinados ao ensino das filhas da elite paulistana e as escolas profissionais dirigidas às jovens da população mais carente, se erigiram as escolas públicas para a educação popular e as Escolas Normais como instituições destinadas a uma classe média que se estruturava no pós-republicano. Compunha-se assim um cenário no qual a educação feminina passou a ser importante, devidamente atrelada, em todos os níveis, à destinação natural das mulheres para lecionar e sempre em estreita relação com o universo doméstico. Apesar das iniciativas visando à igualdade sexual, dentro dos lares a situação das mulheres continuava idêntica, com as esposas e filhas submetidas ao poder patronal que lhes dirigia o destino e ditava as regras de conduta, com o aval da sociedade. Apesar das expectativas alvissareiras da ordem e do progresso do século $\mathrm{XX}$, a higiene, a moralidade e religiosidade, a pureza, os ideais de preservação da raça, da sobrevivência social, estamparam no sexo feminino seu emblema de manutenção da sociedade tradicional e as mulheres continuaram sendo submetidas a padrões comportamentais que serviram para impor barreiras à sua liberdade, autonomia e principalmente sobre a sexualidade. Educar o sexo feminino passou a ser uma necessidade que se impunha cada vez mais diante da sociedade urbanizada que ditava novas regras de convivência no espaço citadino. Para isso a educação se ampliou quantitativamente e escolas começaram a serem inauguradas: colégios católicos, escolas protestantes e escolas públicas, todas herdeiras de um mesmo pressuposto: educar as mulheres para tornar melhores os homens, instruir futuras mães para que contribuíssem para a grandeza da pátria. Deveria haver uma educação básica como alicerce da 
moralidade e em seguimento a esse princípio, as mulheres seriam as principais indicadas para se incumbirem de modelar a infância saudável, patriótica e livre dos vícios que degeneravam a raça e a sociedade.

No campo profissional, as escolas normais deveriam formar professoras para um desempenho pedagógico calcado no humanismo, na competência e nos valores sociais. Essa educação, em nível médio e com objetivo definido, deveria bastar, e as jovens brasileiras cresceriam com o destino profetizado de serem esposas, mães e, em caso de necessidade, professoras. Nesse contexto, a Escola Normal voltava-se para a educação feminina como parte do projeto civilizador da nação e cumpria funções de educar e instruir as futuras esposas e mães, as donas de casa encarregadas da educação familiar e do fortalecimento da família. A ideia de introduzir classes mistas nas escolas passou a ser debatida, mesmo que fosse como experiência pedagógica. Afinal, os dois sexos possuíam a missão de terem destinos compartilhados. Colocar as mulheres para ensinar meninos e meninas cumpria com as expectativas sociais da família exemplar já propostas pela Eugenia e Higienismo e, ao mesmo tempo, vistas com agrado e como a melhor alternativa para ampliar a escolaridade da população, apesar das vozes contrárias a tal prática.

\section{REFERÊNCIAS}

DOCUMENTO. Contrato de trabalho para professoras. San Salvador, 1923 (mimeo).

REIS FILHO, C. dos. A educação e a ilusão liberal. São Paulo: Cortez, 1981.

RODRIGUES, L. M. P. A instrução feminina em São Paulo: subsídios para sua história até a proclamação da República. São Paulo: Faculdade de Filosofia "Sedes Sapientiae", Escolas Profissionais Salesianas, 1962.

WEREBE, M. J. G. Grandezas e misérias do ensino brasileiro. São Paulo: Difusão Européia do Livro, 1963.

Texto recebido em 2 de maio de 2008 .

Texto aprovado em 7 de abril de 2009. 